\title{
Empreendedorismo social como campo em formação no Brasil: o papel das instituições Ashoka, Endeavor e Artemisia
}

\author{
Social entrepreneurship as a field in formation in Brazil: \\ the Ashoka, Endeavor and Artemisia institutions role \\ L'entrepreneuriat social comme un champ en formation au Brésil: \\ le rôle des institutions Ashoka, Endeavour et Artemisia
}

\author{
Emprendedorismo social como campo en formación en Brasil: \\ el papel de las instituciones Ashoka, Endeavor y Artemisia
}

\author{
Alexandre Barbalho ${ }^{1}$ \\ Carolina do Vale Uchoa ${ }^{1}$
}

Recebido em 12/02/2018; revisado e aprovado em 29/07/2018; aceito em 06/08/2018 http://dx.doi.org/10.20435/inter.v0i0.1840

\begin{abstract}
Resumo: O artigo analisa os sentidos que o termo "social" assume nos discursos das organizações e dos empreendedores sociais. A hipótese mais ampla é a de que esses sentidos estão em disputa em um campo em formação e em busca de se afirmar. O presente recorte limita-se a analisar como a noção de "social" é operada por três agências empreendedoras centrais: Ashoka Brasil, Endeavor Brasil e Artemisia. Para tanto recorre-se à teoria dos campos de Pierre Bourdieu.
\end{abstract}

Palavras-chave: empreendedorismo; social; campo.

Abstract: The article analyzes the meanings that the term "social" assumes in the discourses of organizations and social entrepreneurs. The broader hypothesis is that these senses are in dispute in a field in formation and in search of asserting itself. The present clipping is limited to analyzing how the notion of "social" is operated by three central entrepreneurs agencies: Ashoka Brasil, Endeavor Brasil and Artemisia. For that, Pierre Bourdieu's field theory is used.

Keywords: entrepreneurship; social; field.

Resumé: L'article analyse les significations que le terme social prend dans les discours des organisations et des entrepreneurs sociaux. L'hypothèse plus large est que ces sens sont en conflit dans un champ en formation et en quête de s'affirmer. La coupure actuelle se limite à analyser comment la notion de «social» est exploitée par trois agences entrepreneuriales centrales: Ashoka Brasil, Endeavour Brasil et Artemisia. Pour cela, la théorie des champs de Pierre Bourdieu est utilisée.

Mots-clés: entrepreneuriat; social; champ.

Resumen: El artículo analiza los sentidos que el término "social" asume en los discursos de las organizaciones y de los emprendedores sociales. La hipótesis más amplia es la de que estos sentidos están en disputa en un campo en formación y en busca de afirmarse. El presente recorte se limita a analizar cómo la noción de "social" es operada por tres agencias empresariales centrales: Ashoka Brasil, Endeavor Brasil y Artemisia. Para ello se recurre a la teoría de los campos de Pierre Bourdieu.

Palabras clave: empreendedorismo; social; campo.

\section{INTRODUÇÃO}

O empreendedorismo social é frequentemente citado como um setor novo e em rápida expansão. Diversas matérias publicadas na mídia revelam esse fenômeno, destacando que os negócios sociais começam a se profissionalizar e estão revolucionando o campo empresarial. Não há, porém, dados estatísticos que mensurem esse avanço ao longo do tempo, nem mesmo que revelem a quantidade desse tipo de "negócios" existente hoje no Brasil.

\footnotetext{
${ }^{1}$ Universidade Estadual do Ceará (UECE), Fortaleza, Ceará, Brasil.
} 
Um dos poucos estudos sobre a área foi publicado em 2015 pelo Programa das Nações Unidas para o Desenvolvimento (PNUD). Intitulado Mercados Inclusivos no Brasil - Desafios e oportunidades do ecossistema de negócios (PNUD, 2015), o relatório traz um diagnóstico que revela a tendência de crescimento do setor, assim como seus obstáculos. O estudo identifica, entre outras coisas, a falta de conhecimento sobre o conceito e a prática de negócios inclusivos, muitas vezes confundidos com responsabilidade social corporativa. O cenário descrito revela o empreendedorismo social como um setor que ainda está em busca de legitimação e permanece parcialmente desconhecido e com contornos imprecisos.

Nesse contexto, o adjetivo "social" tem o efeito de criar uma divisão, delimitando um segmento ou categoria específica no interior do empreendedorismo. Essa propriedade, porém, auxilia pouco na tarefa de traçar um recorte nítido, capaz de distinguir as peculiaridades do setor e agrupar certo número de iniciativas e agentes, tantos são os seus sentidos. Dardot e Laval (2016), por exemplo, observam a ambiguidade presente na ideia de "social" que se manifesta na expressão "economia social de mercado". Esse termo, apontam os autores, indica tanto uma fé no resultado benéfico do processo econômico de mercado, quanto a percepção de que a sua ordem não é natural, mas socialmente construída e que necessita de regulagem (do Estado e da própria sociedade) para funcionar bem.

A partir desse quadro, investigaremos neste artigo quais os sentidos específicos que o termo "social" assume nos discursos das organizações e dos empreendedores sociais. Nossa hipótese mais ampla é a de que esses sentidos estão em disputa em um campo em formação e, portanto, em busca de se afirmar. Obviamente, trata-se de uma tarefa que extrapola o âmbito deste trabalho. Nossa contribuição, nesse momento, será a de analisar como a noção de "social" é operada por três agências empreendedoras consideradas centrais e exemplares nesse campo, que atuam como parte de um "movimento" que já está em curso e se projeta no futuro, anunciando novos "mundos possíveis": Ashoka Brasil, Endeavor Brasil e Artemisia.

Para pensarmos como se dá esse processo de diferenciação e de legitimação do empreendedorismo social enquanto segmento específico, com regras, estratégias discursivas, vocabulários, princípios de hierarquização e ethos próprios, recorreremos à teoria dos campos de Pierre Bourdieu. Por sua vez, a noção que adotamos de campo aproxima-se daquilo que Reis e Grill, em diálogo com o sociólogo francês, optam por chamar de "domínio social". O recurso a essa noção nos parece útil por nomear "circunstâncias nas quais não é possível pressupor elevados graus de institucionalização e autonomização", mas onde se observa um espaço delimitado "por injunções legítimas, nas quais atuam agentes portadores de características e trunfos variados de autoridade, que os habilitam a circular entre elas e a produzir e impor representações sobre a vida social" (REIS; GRILL, 2016, p. 35).

Por isso, optamos por designar o empreendedorismo social como um "campo em formação", buscando, com isso, evidenciar tanto os processos de diferenciação interna no âmbito do empreendedorismo em geral quanto as relações de interdependência que mantêm com outras esferas sociais. Ou seja, um campo que busca alcançar uma relativa autonomia, desenvolvendo estratégias que visam dar-Ihe legitimidade, por meio de uma série de agentes - individuais e institucionais - específicos que compartilham de certos interesses e habitus próprios e, ao mesmo tempo, entram em disputa pelas posições mais elevadas, inclusive, pelo direito de estabelecer as regras e ditar as hierarquias.

Esse entendimento converge com o de Hervieux, Gedajlovic e Turcotte (2010), para quem o empreendedorismo social constitui um "domínio institucional emergente", que se encontra na 
interseção entre dois campos estabelecidos - do empreendedorismo e do ativismo social - e busca se estabelecer como um novo campo, formado a partir da união dessas duas lógicas distintas. É necessário investigar, ressaltam os autores, se o empreendedorismo social está conseguindo chegar a um acordo quanto às práticas que devem ser aceitas como pertencentes a ele. É a esse desafio que iremos contribuir com as análises que seguem.

Para tanto, fixaremos na primeira parte o conceito de empreendedorismo, para, em seguida, abordarmos o universo conceitual do empreendedorismo social tal como ele se dá no espaço acadêmico. Na seção seguinte, discutiremos o sentido do "social" nesse campo em formação, o que nos dará suporte para analisar, na parte final, os valores defendidos pelas instituições empreendedoras Ashoka Brasil, Endeavor Brasil e Artemisia e seus papéis de agentes legitimadores.

\section{POR UM CONCEITO DE EMPREENDEDORISMO}

Para examinarmos de forma mais detida como se dá esse processo de singularização do empreendedorismo social, precisamos partir de uma definição do que seja "empreendedorismo" de uma forma em geral. Há um amplo debate acerca do tema, mas tomaremos como base apenas alguns referenciais por conta do grau de difusão e "popularização" que alcançaram.

Dentre eles, destaca-se a definição dada por Schumpeter (1984) a partir do caráter inovador do empreendedor, visto aqui como promotor do desenvolvimento econômico. Enquanto elemento dinâmico da economia, ele deve desempenhar o papel de romper com os limites tradicionais, gerando um desequilíbrio inicial, que depois se consubstanciará em uma nova tradição. Por isso mantém uma relação ambígua com as instituições: se, por um lado, depende do apoio destas (das instituições políticas, econômicas, de crédito etc.) para se desenvolver, é também das instituições (aqui entendidas como conjuntos de práticas e valores relativamente estáveis) que provém um movimento de oposição e resistência às inovações.

Percebemos, então, a diferença do empreendedor em relação ao administrador ou empresário. Administrar uma empresa, fazê-la crescer e "modernizar" sua produção e organização são atividades que podem ser comuns aos dois, mas, para o empreendedor, o elemento fundamental, segundo a concepção schumpeteriana, é a inovação: em uma situação de concorrência, o empresário adapta-se constantemente, enquanto o empreendedor inova. Além disso, para Schumpeter (1984), o empreendedor não necessariamente é proprietário da empresa e nem forma uma classe social (diferente do capitalista), pois não é um estado duradouro, mas uma condição restrita aos raros momentos em que inovações "revolucionárias" podem ser levadas a cabo.

Dardot e Laval (2016) afirmam que o empreendedorismo - e a figura do empreendedor, ou homem-empresa, como chamam - é o princípio de conduta mais essencial à ordem capitalista. No neoliberalismo, mais do que a construção de uma situação econômica que se aproxime da livre concorrência, é necessário haver uma política que molde os sujeitos para torná-los empreendedores que saibam aproveitar as oportunidades de lucro e estejam dispostos a entrar no processo permanente da concorrência. Assim, o empreendedor é definido como o indivíduo capaz de detectar e aproveitar oportunidades de lucro, a partir das informações de que dispõe e movido pela concorrência, em um processo de permanente de aprendizagem e de formação de si.

Essas visões convergem no chamado neoschumpeterismo, que se difunde a partir dos anos 1980, em que a referência à figura do empreendedor-inovador ganha um alcance apologético, 
tornando-se um dos elementos da "vulgata gerencial". A gestão empresarial passa a ser vista como a verdadeira fonte do progresso, capaz de gerar uma sociedade de empreendedores, cuja característica central é a sua adaptabilidade e mudança perpétua. Essa sociedade busca difundir o espírito empreendedor em todos os domínios da ação coletiva, fazendo da inovação o princípio universal de organização. A educação e a imprensa desempenham um papel determinante na difusão desse "novo modelo humano genérico" (DARDOT; LAVAL, 2016).

O empreendedorismo social parece manter, em muitos aspectos, uma linha de continuidade com essa visão, como veremos nas seções que seguem. Comecemos por examinar qual a definição hegemônica vigente no campo acadêmico, campo, por excelência, gerador de discurso competente e legitimador.

\section{O OLHAR ACADÊMICO SOBRE O EMPREENDEDORISMO SOCIAL}

Uma busca em bases de dados de pesquisas científicas ${ }^{2}$ revela o grande volume de trabalhos que utilizam o termo "empreendedorismo social" e equivalentes ("empreendedores sociais", "negócios sociais"). Basta um exame um pouco mais atento, porém, para perceber que a maior parte deles trata de temáticas tão diversas como experiências ligadas ao terceiro setor, à economia solidária, ao cooperativismo, a ações de responsabilidade social corporativa.

Essa indeterminação remete, segundo Rosolen, Tiscoski e Comini (2014), às próprias origens do conceito. Difundida inicialmente nos Estados Unidos, a expressão "social entrepreneuship" era usada com um significado abrangente, servindo para nomear qualquer atividade inovadora com objetivo social, englobando assim as práticas desenvolvidas por diversos tipos de organizações envolvidas em "atividades socialmente benéficas", tanto do setor privado, como do chamado terceiro setor, além das "organizações híbridas". O emprego desse termo - substituindo o uso, por exemplo, de "filantropia" - sinalizava para uma mudança nas formas de atuação das organizações não governamentais, que passavam a se aproximar de uma orientação de mercado, visando se tornarem menos dependentes de doações e de subvenções estatais, e expressava, ao mesmo tempo, uma crescente confiança no poder da concorrência e do lucro como promotores da eficiência e da inovação.

Hervieux, Gedajlovic e Turcotte (2010), por sua vez, avaliam que a literatura científica relativa ao empreendedorismo social tem se limitado a estudos de casos descritivos, havendo uma clara lacuna na construção teórica. Além disso, quando buscam definir essa prática, boa parte desses estudos baseia-se nas teorias clássicas do empreendedorismo, utilizando um quadro de referências que se revela incompleto para dar conta do fenômeno, sobretudo porque deixa de fora a questão da legitimação do empreendedorismo social como um campo organizacional.

No que se refere à produção acadêmica nacional, a maior parte das pesquisas sobre empreendedorismo social tem sido desenvolvida no âmbito dos cursos de Administração e Gestão. Barki et al. (2015), pesquisadores ligados à Administração, oferecem um panorama geral desse cenário e assumem uma visão que nos parece hegemônica nessa disciplina. O surgimento desse setor é atribuído ao propósito, por parte dos empreendedores, de diminuir as vulnerabilidades e desigualdades sociais no mundo, problemas esses que são decorrentes, segundo sua interpretação, de "lacunas" na atuação dos governos. Nesse cenário, é conferido aos negócios sociais o papel de "integração" entre modelos de negócios sustentáveis e as "necessidades da sociedade".

\footnotetext{
${ }^{2}$ Realizamos busca nas plataformas Google Acadêmico e Scielo.
} 
De um modo geral, observamos, nesses estudos, a preocupação em contribuir com o desenvolvimento do empreendedorismo social, buscando definir meios pelos quais as empresas podem melhorar suas práticas. Eles trazem, portanto, de forma mais ou menos explícita, uma visão positiva do fenômeno e a crença na sua capacidade de construir uma sociedade mais justa e igualitária. Como observa Vander Casaqui, "trata-se da perspectiva dos realizadores ou de adesão ao seu ideário - sem o distanciamento crítico e a visão sistêmica necessários para a compreensão do papel atribuído a esse agente em nosso tempo" (CASAQUI, 2015, p. 206-7).

Não se procura compreender, portanto, o contexto em que emerge o empreendedorismo social como prática social desenvolvida por agentes com múltiplos interesses e valores - por vezes conflitantes e contraditórios entre si - e inserida em lutas hegemônicas que envolvem agentes locais e globais, na definição dos "problemas sociais" (suas origens e suas características) e das formas de minimizá-los ou solucioná-los; ou como se formam as crenças na primazia dada ao setor privado e ao "mercado" para a resolução dos problemas sociais - em detrimento, por exemplo, do Estado e de outras formas de organização social.

\section{0 "SOCIAL" COMO MARCA DISTINTIVA}

Como dito acima, as definições acerca do conceito de empreendedorismo social não revelam as tensões e disputas que atravessam esse campo em sua dimensão prática. Essas dizem respeito, entre outros aspectos, a quem - que agentes ou que empreendimentos - pode ser considerado legítimo membro desse campo e, assim, usufruir de seus benefícios, que envolvem desde aspectos simbólicos - a "imagem" pública do empreendedor preocupado com o "social" - até aspectos econômicos - como o direito de participar de programas de financiamento específicos para essa área, de concorrer em concursos e premiações etc.

Como observa Bourdieu (2007; 2003a; 2003b), uma das formas mais visíveis da autonomia do campo é sua capacidade de "refratar", de retraduzir sob uma forma específica as pressões ou demandas externas. Quanto mais autônomo for um campo, maior seu poder de refração, de modo que as imposições externas são transfiguradas a ponto de se tornarem irreconhecíveis. Trata-se, então, de um estado da distribuição do capital específico - ou seja, do capital que é válido para aquele campo específico, enquanto fundamento do poder ou da autoridade reconhecidos neste, só convertível em outras espécies de capital em condições também específicas. Assim, aqueles que, num estado determinado dessa relação de força, monopolizam o capital específico, inclinam-se para estratégias de conservação dessa estrutura. Já os menos providos de capital (que frequentemente são os recém-chegados e os mais jovens) tendem a adotar estratégias de subversão.

Porém todos os agentes pertencentes a um campo compartilham certos interesses fundamentais, os quais estão ligados à própria existência do campo. Por isso, para além dos antagonismos que podem haver entre eles, subjaz uma cumplicidade objetiva. A luta pressupõe um acordo entre os antagonistas sobre aquilo pelo que merece que se lute, ainda que esse consenso seja tratado como algo óbvio, aceito tacitamente.

Aqueles que pleiteiam ingressar em um campo precisam dar provas tanto do reconhecimento do valor do jogo quanto do conhecimento dos princípios de funcionamento deste. As estratégias de subversão, portanto, devem permanecer dentro de certos limites, não colocando em questão os fundamentos e as crenças sobre os quais assenta o jogo, sob pena de exclusão. 
Dito isto, qual seria então o capital específico do empreendedorismo social e como se dá sua distribuição no campo? Como parte do campo geral do empreendedorismo, e sendo este parte do campo econômico, é evidente que o capital econômico mantém-se como fator decisivo, tanto para ingresso - na medida em que é necessário dispor de certa quantia de capital financeiro tanto para iniciar ou investir em novos negócios, quanto para adquirir a formação tida como necessária para tornar-se um membro legítimo - mas também como medida de sucesso dentro do campo - a "sustentabilidade" econômica dos negócios é um dos parâmetros utilizados para definir quem são as figuras dominantes nesse setor.

Contudo uma das características pelas quais o empreendedorismo social busca se distinguir é justamente pela menor importância relativa dada ao capital econômico. Por isso, insiste-se em seu caráter acessível mesmo àqueles que não fazem parte dos estratos superiores: vários e válidos são os relatos utilizados para demonstrar que, mesmo com baixo ou quase nenhum investimento inicial, uma "grande ideia" pode vir a se tornar um "negócio de sucesso". Além disso, conforme esses discursos, esse êxito não deve ser medido exclusivamente ou prioritariamente pelos resultados financeiros, mas também pela satisfação em dedicar-se a uma atividade que "faz sentido" e de cujos resultados é possível se orgulhar.

Dessa forma, outras modalidades de capital - como o capital cultural e capital social - assumem importância central nesse campo em formação, o que de resto não é uma exclusividade sua. Em sua análise do campo econômico, Bourdieu (2014) aponta a necessidade de mobilizar um sistema de conceitos que inclui os de capital cultural, capital social e capital simbólico, além dos de habitus e campo.

Contudo, diferentemente de outros setores profissionais, em que diplomas e títulos acadêmicos são reconhecidos como capital cultural, observa-se aqui a valorização de certo tipo de conhecimento prático, obtido por meio da vivência em diferentes meios sociais. Viagens internacionais, trabalhos voluntários que os colocam em contato com diferentes realidades, bem como experiências profissionais diversas, são destacados como etapas ou "eventos" importantes na formação de um empreendedor social (em contraste com os conhecimentos acadêmicos que são frequentemente desvalorizados como "distantes da realidade"). Já o capital social, que consiste na capacidade de estabelecer conexões estratégicas com diferentes públicos, é um dos fatores essenciais para o êxito dos negócios sociais, na medida em que estes dependem fortemente da habilidade para "engajar pessoas" em torno de projetos ou causas (conquistando apoiadores, seguidores, colaboradores voluntários etc.).

O empreendedorismo social é, portanto, caracterizado por certa composição desses três tipos de capital - econômico, cultural e social - que, articulados, compõem o capital simbólico dos empreendedores sociais - ou seja, o reconhecimento e prestígio social que conferem a estes a capacidade de "fazer ver" e "fazer crer" (BOURDIEU, 2003b). Esse conjunto de agentes e agenciamentos constitui aquilo que, no jargão próprio do campo, é chamado de "ecossistema empreendedor", dos quais podemos citar, além dos próprios empreendedores sociais, programas de formação e capacitação, aceleradoras e incubadoras de negócios sociais, fundos de investimentos específicos, consultorias, mentorias, fundações internacionais que patrocinam negócios sociais, agentes governamentais que atuam nos programas de estímulo ao empreendedorismo, premiações, concursos, eventos empresariais, publicações especializadas etc. Cada um desses agentes dispõe de certo volume de capital e tem a capacidade de interferir na distribuição desse capital entre os demais agentes e, portanto, nas posições que cada um ocupa, em uma dinâmica complexa. 
Como já dito, não temos o objetivo aqui de fazer uma análise geral do campo, mas examinar o papel formador exercido por três organizações - Ashoka Brasil, Endeavor Brasil e Artemisia -, considerando que estas assumem várias das funções apresentadas anteriormente, ajudando a difundir os conceitos, os valores e as práticas do empreendedorismo social não apenas internamente, mas estabelecendo interfaces entre este e outros domínios sociais.

\section{CONSTRUINDO O CAMPO DO EMPREENDEDORISMO SOCIAL: A POSIÇÃO DOS AGENTES ENDEAVOR BRASIL, ARTEMISIA E ASHOKA BRASIL}

Como afirma Casaqui, o campo do empreendedorismo social é constituído e alimentado "por processos discursivos, por estratégias midiáticas, por regimes de visibilidade" (CASAQUI, 2016, p. 207). Diversos agentes globais e locais, individuais e coletivos, compõem a complexa teia comunicacional na qual suas práticas são significadas e legitimadas. Esses discursos ajudam a disseminar a crença no potencial revolucionário do empreendedorismo social. Dey e Steyaert (2010), por sua vez, afirmam que as narrativas hegemônicas acerca destse tipo de empreendedorismo têm em comum uma retórica utópica e uma ênfase na "novidade". Elas frequentemente trazem "mitos fundadores" que se apresentam como uma ruptura com o passado, uma atividade nova e inteiramente sem precedentes.

Daí a importância, como recurso empírico, das autodefinições desses agentes - individuais e coletivos. Vejamos, então, como se organizam esses discursos produzidos pelas organizações citadas: Endeavor Brasil, Artemisia e Ashoka Brasil. Elas têm em comum o fato de atuarem tanto na difusão de informações, dados e opiniões acerca do empreendedorismo social - por meio da publicação, em suas plataformas digitais, de notícias, reportagens, artigos, entrevistas, estudos, pesquisas etc. - quanto no apoio direto a iniciativas de empreendedores sociais - oferecendo consultorias, mentorias e atividades educacionais e formativas, como cursos, oficinas, workshops, entre outras.

Optamos por chamá-las, por isso, de organizações de apoio ao empreendedorismo social. Elas não são, devemos ressaltar, as únicas. Há um vasto número de sites e portais informativos sobre o tema, bem como de instituições educacionais que fornecem cursos e treinamentos voltados para o setor, os quais contribuem, também, para a conformação do campo. Consideramos, contudo, por meio de pesquisa exploratória prévia, que esses três exemplos compõem uma amostra significativa do setor, tanto pelo seu caráter precursor e grau de maturação - todas contabilizam mais de uma década de atuação, em contraste com outras iniciativas, em geral mais recentes - bem como pela variedade de atividades que desenvolvem.

Reportagens publicadas em grandes veículos de comunicação mostram que essas três organizações são tidas como fontes autorizadas a falar sobre o empreendedorismo social, seja fornecendo dados que apontam o crescimento geral do setor, seja indicando as áreas mais promissoras, servindo como orientação para futuros empreendedores ou investidores. Em alguns casos, a própria atuação dessas organizações é tema das matérias jornalísticas, que destacam seu papel como impulsionadoras do campo.

Apesar das semelhanças nos papéis que desempenham no setor, essas três organizações apresentam características um tanto distintas: a Endeavor é a única que é voltada também para o estímulo ao empreendedorismo em geral, tratando da vertente social apenas como um dos tipos possíveis de negócios. Já as outras duas - Artemisia e Ashoka - dedicam-se exclusivamente 
a promover o empreendedorismo social. Além disso, Endeavor e Ashoka são iniciativas de alcance global, estando presentes em vários países, enquanto a Artemisia, apesar de fundada por uma empresária norte-americana e ligada a um fundo de investimentos com atuação internacional, é de origem brasileira e tem sua atuação restrita ao âmbito nacional.

\subsection{Endeavor Brasil}

A Endeavor apresenta-se como a "organização líder no apoio a empreendedores de alto

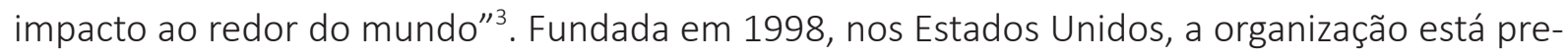
sente hoje em 22 países, sendo que, desde o ano 2000, conta com uma representação no Brasil, onde possui oito escritórios.

No Endeavor Impact Report 2013-20144, a cofundadora Linda Rottenberg narra o momento em que decidiu criar a organização como um "crazy moment", situação que, segundo ela, marca a trajetória de todos os empreendedores, na qual estes "devem escolher entre o seguro e esperado, e o inseguro e desconhecido" (tradução nossa). Ela e o irmão decidiram "perseguir o sonho" de criar uma organização que buscaria encontrar empreendedores de alto impacto para conectá-los com mentores de várias partes do mundo e oferecer serviços de apoio. Empreendedores de alto impacto são descritos como aqueles que têm grandes ideias, com potencial para construir negócios que gerem resultados e com habilidade para inspirar outras pessoas. Essa organização tornaria possível para esses "sonhadores" alcançar seus objetivos mais rapidamente. Rottenberg define a "missão" da Endeavor como a de "garantir que os crazy moments de outros empreendedores resultem em um tremendo sucesso tanto para eles quanto para suas comunidades mais amplas" (tradução nossa) ${ }^{5}$.

Já a Endeavor Brasil foi fundada pelos empresários Beto Sicupira, Jorge Paulo Lemann e Marcel Telles, descritos, em matéria do portal de notícias Época Negócios (2015), como "trio de bilionários brasileiros" que "comanda o fundo de investimentos $3 \mathrm{G}$ e é um dos controladores da ABInBev, empresa resultante da fusão entre Ambev e a belga Interbrew", além de serem sócios de várias outras empresas nacionais e multinacionais. A organização conta ainda com a parceria e apoio de bancos e outras grandes corporações e realiza campanhas de arrecadação de doações individuais ${ }^{6}$.

O "Manifesto Endeavor" apresenta a visão da organização acerca do papel do empreendedorismo, destacando o potencial transformador deste na geração de empregos e riqueza, mas também na criação de inovações que "revolucionam o jeito de pensar". O texto destaca os atributos dos grandes empreendedores - ousadia e pragmatismo - e define como propósito da Endeavor a criação de uma rede com "as mentes mais brilhantes de nosso tempo" que "amplifica o sonho empreendedor":

\footnotetext{
${ }^{3}$ Disponível em: www.endeavor.org.br. Acesso em: 22 maio 2017.

${ }^{4}$ Disponível em: http://endeavor.uberflip.com/i/414924-endeavor-impact-report-2013-2014/1?. Acesso em: 22 maio 2017.

${ }^{5}$ Original em inglês: "Our mission is to ensure that entrepreneurs' crazy moments result in tremendous success both for them and for their broader communities". Disponível em: http://endeavor.uberflip.com/i/414924-endeavorimpact-report-2013-2014/1?. Acesso em: 22 maio 2017.

${ }^{6}$ Alguns dos parceiros citados são: banco Santander, bolsa de valores BM\&F Bovespa, banco de investimento brasileiro BTG Pactual, banco suíço de investimento Credit Suisse, banco norte-americando J.P. Morgan, a fabricante de computadores norte-americana Dell, dentre outros. Disponível em: https://endeavor.org.br/institucional/quemapoia/. Acesso em: 22 maio 2017.
} 
Sabemos que o empreendedor de alto impacto não cresce sozinho. Cresce continuamente e faz crescer, gera empregos e riqueza, cria inovação e referência, ganha escala e revoluciona o jeito de pensar, fazendo crescer pessoas, o mercado e as possibilidades de transformação da sociedade. É essa causa que nos motiva a trabalhar juntos no nosso propósito. Grandes empreendedores, líderes empresariais e especialistas juntos. (AZEVEDO, 2015).

Apesar de não ser voltada especificamente para o empreendedorismo social, a Endeavor tem sido uma das principais disseminadoras desse segmento no Brasil, divulgando conteúdos referentes a ele em suas plataformas digitais, promovendo pesquisas e ajudando a pautar notícias e reportagens sobre o tema veiculadas em diversos órgãos de comunicação.

\subsection{Artemisia}

A Artemisia é uma Organização da Sociedade Civil de Interesse Público (Oscip), fundada em 2004, pela empresária norte-americana Kelly Michel, com o objetivo de apoiar "o desenvolvimento de talentos e empreendedores na criação e desenvolvimento de negócios de impacto que ajudam a resolver os problemas sociais da população de baixa renda no Brasil" "7. A instituição afirma ter sido pioneira na disseminação desse conceito, tendo contribuído para torná-lo mais conhecido no país. A visão da organização acerca do papel do empreendedorismo social, e de seu próprio papel no desenvolvimento desse setor, é resumida no documento intitulado "Manifesto Artemisia"8.

O texto enfatiza a ideia de um mundo em transformação, em que o futuro é projetado como uma situação na qual haverá "iguais oportunidades para todos". Se esse futuro ideal ainda não foi alcançado é porque alguns setores da sociedade permanecem apegados a velhos hábitos e modelos de pensamento e ação obsoletos. Para que esse futuro possa emergir, é necessário, de acordo com a visão expressa no texto, desfazer-se da ideia de que "ganhar dinheiro" e "fazer a diferença" ou criar "negócios" e promover "impacto social" são atividades e propósitos incompatíveis - eles devem, ao contrário, ser integrados, de modo que não é preciso escolher entre um e outro, e sim "aspirar ao melhor de dois mundos".

O papel da Artemisia é definido como inspirar, capacitar e potencializar talentos, bem como contribuir para tornar os negócios sociais mais conhecidos, reafirmando-os como uma "tendência emergente na sociedade brasileira". Para isso, diz o Manifesto, é necessário assumir riscos e romper com padrões. Os empreendedores sociais, por sua vez, são apresentados como os únicos capazes de conduzir o Brasil para esse futuro ansiado: são eles, "e somente eles", que podem criar os negócios que vão mudar o país. E, além de gerar transformações sociais capazes de melhorar a vida da "população de baixa renda", os negócios sociais cumprem o papel de conectar os criadores destes com seu "propósito pessoal", fazendo com que trabalhem com "permanente alegria e encantamento".

Os recursos da Artemisia vêm de um fundo de investimentos, a Potência Ventures (também pertencente a Kelly Michel), de doações espontâneas e da parceria com grandes empresas. A empresária também é uma das sócias, juntamente com os empresários Daniel Izzo e Antonio

\footnotetext{
${ }_{7}^{7}$ Disponível em: http://artemisia.org.br/conteudo/artemisia/historia.aspx. Acesso em: 22 maio 2017.

${ }^{8}$ Disponível em: http://artemisia.org.br/conteudo/artemisia/nosso-manifesto.aspx. Acesso em: 22 maio 2017.
} 
Ermírio de Moraes Neto ${ }^{9}$, do Vox Capital, "fundo de capital risco para empresas brasileiras que primam pela redução da desigualdade social"10.

Além de atuar na difusão de informações sobre o setor, a organização desenvolve programas de apoio e investimento direto em negócios sociais. Em 2010, lançou a "Aceleradora Artemisia", voltada para "selecionar empreendedores com forte intenção de crescer e gerar impacto social, e oferecer-Ihes suporte intensivo na busca de soluções para consolidação de seus modelos ${ }^{11 "}$. No mesmo ano, a organização deu início às atividades do Centro de Formação em Negócios de Impacto Social, que, "com base numa tecnologia inovadora, que combina teoria e prática junto às comunidades de baixa renda, forma talentos para atuarem nesse novo campo ${ }^{12 "}$.

Em 2011, criou o "Movimento Choice", para incentivar jovens universitários a se tornarem empreendedores sociais e ingressarem no mercado de trabalho dos negócios de impacto social. Esses jovens participam de uma imersão no universo do business de impacto social por quatro meses $^{13}$, com encontros presenciais e acompanhamento online para elaboração e aprimoramento dos modelos de negócios, incentivando o networking. Segundo a instituição, esta já é a "maior rede de jovens engajados em transformar o jeito de fazer negócios no Brasil ${ }^{14 \prime \prime}$.

O site da organização disponibiliza, além de informações sobre cada um desses programas, notícias e artigos referentes a temas diversos ligados ao empreendedorismo social (eventos, prêmios, pesquisas, criação de novos negócios etc.), tanto produzidos pela própria equipe da plataforma quanto veiculados em outros meios de comunicação.

\subsection{Ashoka Brasil}

A Ashoka ${ }^{15}$, organização criada em 1980 pelo norte-americano Bill Drayton, define-se como "uma organização mundial, sem fins lucrativos, pioneira no campo da inovação social, trabalho e apoio aos empreendedores sociais - pessoas com ideias criativas e inovadoras capazes de provocar transformações com amplo impacto social”16. Ela afirma ser a criadora do termo empreendedorismo social e ter caracterizado este como um campo de trabalho.

A organização, que iniciou sua atuação na Índia e no Brasil (neste último, em 1986) e hoje está presente em 85 países, realiza um processo de busca e seleção, com etapas nacionais e internacionais, de empreendedores que "são líderes no campo em que atuam e estão influen-

\footnotetext{
${ }^{9}$ Segundo matéria divulgada no site Projeto Draft, Daniel Izzo é ex-executivo de multinacional (era "gerente de produtos da Sundown, um dos principais produtos da gigante global Johnson \& Johnson") e Antonio Ermírio de Moraes Neto é membro da família proprietária do Grupo Votorantim, multinacional brasileira e um dos maiores conglomerados empresariais do país. Disponível em: http://projetodraft.com/cansei-de-tornar-os-ricos-aindamais-ricos-diz-daniel-izzo-da-vox-capital-que- investe-em-negocios-sociais/. Acesso em: 22 maio 2017.

${ }^{10}$ Disponível em: http://projetodraft.com/conheca-a-artemisia-organizacao-ha-10-anos-no-brasil- cuidando-dequem-quer-cuidar-do-mundo/. Acesso em: 22 maio 2017.

${ }^{11}$ Disponível em: http://artemisia.org.br/conteudo/artemisia/historia.aspx. Acesso em: 22 maio 2017.

12 Idem.

${ }^{13}$ Disponível em: http://projetodraft.com/conheca-a-artemisia-organizacao-ha-10-anos-no-brasil- cuidando-dequem-quer-cuidar-do-mundo/. Acesso em: 22 maio 2017.

${ }^{14}$ Disponível em: http://choice.org.br/\#quem-somos. Acesso em: 22 maio 2017.

${ }^{15}$ O termo Ashoka significa, em sânscrito, "ausência de sofrimento". Disponível em: http://brasil.ashoka.org/quemsomos. Acesso em: 22 maio 2017.

${ }^{16}$ Disponível em: http://brasil.ashoka.org/quem-somos. Acesso em: 22 maio 2017.
} 
ciando políticas públicas a fim de gerar mudanças sistêmicas" ${ }^{17}$. Os selecionados - chamados de "Fellows Ashoka" - passam a integrar uma rede de intercâmbio de informações e colaboração, composta hoje por mais de três mil empreendedores (no Brasil, segundo informações disponíveis no site da organização, são 370 "fellows"). Seu diferencial é, além do "rigoroso e qualificado processo de seleção", o apoio oferecido a esses empreendedores "nos diferentes estágios de desenvolvimento de suas ideias" e "o investimento realizado em pessoas, não em projetos" $^{18}$.

O processo de seleção dos "Fellows Ashoka" está "centrado na pessoa e na solução inovadora de amplo impacto social" e se baseia na avaliação da trajetória pessoal e profissional do candidato, tendo por base os critérios: inovação, perfil empreendedor, criatividade, impacto social e "fibra ética". A "Visão" da instituição traz uma síntese de sua concepção de empreendedorismo social como "modo de ver o mundo e de agir", com o qual "todos podemos agir como protagonistas da transformação social positiva"19. No Relatório Institucional 2015-2016²0, a Ashoka Brasil define assim sua atuação:

Atuamos como uma organização global de investimento em ideias inovadoras e seus autores, apoiando a construção do ecossistema do empreendedorismo social no Brasil, identificando líderes visionários com ideias criativas capazes de provocar transformações com amplo impacto social. Nós também criamos uma comunidade global para assegurar a replicação dessas ideias em larga escala, fomentando a colaboração e convergência entre os setores social, privado e público, definindo assim o empreendedorismo social como campo de trabalho. (ASHOKA BRASIL, 2016).

Nos dois textos, a organização enfatiza seu caráter global e seus múltiplos papéis de investimento, apoio e identificação de líderes. Chama a atenção ainda a ideia de colaboração e convergência entre os setores social, privado e público e a definição do empreendedorismo social como um campo de trabalho. A ideia de que o "protagonismo na transformação social" pode ser uma qualidade de todos é um argumento central no discurso institucional da Ashoka, que é associada aqui às possibilidades de participação abertas pelas novas tecnologias.

\section{CONSIDERAÇÕES FINAIS}

A partir das análises acima, podemos sistematizar alguns dos valores centrais que sustentam a formação do campo do empreendedorismo social. A inovação, por exemplo, é um de seus elementos centrais, sendo muitas vezes associada ao termo criatividade, que a vincula à qualidade subjetiva dos agentes. A capacidade de detectar oportunidades de novos negócios (ver os "problemas" sociais como novos mercados a serem explorados) é outro atributo sempre destacado, assim como a ênfase dada à gestão (que deve ser, também ela, inovadora) e ao "empreendedorismo de si", que leva à visão de si próprio como uma "empresa".

Por outro lado, termos como "desenvolvimento econômico" e "concorrência", comuns nas definições de empreendedorismo, perdem espaço no vocabulário dos empreendedores sociais.

\footnotetext{
${ }^{17}$ Disponível em: http://brasil.ashoka.org/quem-somos. Acesso em: 22 maio 2017.

18 Idem.

${ }^{19}$ Idem.

${ }^{20}$ Disponível em: http://brasil.ashoka.org/sites/brasil.ashoka.org/files/Ashoka\%20Brasil\%20\%20Relatorio\%20 Institucional\%20(Dezembro\%202016).pdf. Acesso em: 22 maio 2017.
} 
A perspectiva do primeiro não parece mais ser suficiente para fornecer as justificativas morais necessárias para engajar os profissionais nas práticas capitalistas: é preciso, aqui, que os negócios ataquem diretamente os problemas sociais, gerando impactos imediatos. Já a concorrência deixa de ser citada como fator essencial para a inovação e em seu lugar surgem a cooperação e a colaboração como as atitudes mais propícias para a liberação da criatividade e a conjugação de diferentes saberes e visões que levam ao surgimento de negócios realmente inovadores (o que, porém, entra em choque com a grande quantidade de concursos e premiações, de caráter claramente competitivo, que marca a dinâmica desse campo).

Em alguns momentos, os empreendedores sociais colocam-se como "modelos" inspiradores para as empresas tradicionais, que teriam "muito o que aprender" com eles. Em outros, ressalta-se a recusa em se tornar "grande" e, ao invés de crescimento, usa-se com frequência o termo "escalabilidade", que indica a capacidade do negócio de expandir suas atividades sem elevar os custos, podendo assim aumentar o faturamento e permanecer "pequena" - por meio, por exemplo, do desenvolvimento de produtos ou soluções que são "replicáveis" e, assim, podem obter receitas através do licenciamento de direitos de uso (o que ocorre principalmente com as startups de tecnologia).

Essa não é uma característica exclusiva dos negócios sociais. Ao contrário, a redução e flexibilização da "força de trabalho" são tidas como exigências concorrenciais gerais no capitalismo contemporâneo, em que, como aponta Bauman (2008), dá-se uma ruptura nos laços de dependência entre capital e trabalho. Essa volatilidade, porém, parece encontrar lugar privilegiado no campo do empreendedorismo social, pelo fato de ser justificada, nesse caso, não apenas pela necessidade de reduzir os custos operacionais e maximizar a lucratividade, mas, em sentido oposto, como forma de dar maior autonomia às iniciativas sociais, permitindo que estas se valham de formas alternativas de obtenção de recursos, como financiamentos coletivos para projetos de curto prazo.

Porém, os discursos de afirmação do empreendedorismo social, presentes em instituições consagradas e consagradoras como Ashoka Brasil, Endeavor Brasil e Artemisia, não deixam claro em que condições esse protagonismo pode emergir e o que leva alguns indivíduos a adquirirem os atributos necessários para comporem o seleto grupo de "líderes visionários" que as organizações buscam identificar e selecionar. Uma resposta a essas questões só podem vir, na realidade, de análises mais amplas sobre esse campo em formação, procurando fixar suas regras e estratégias discursivas, bem como seus princípios de legitimação, diferenciação e hierarquização.

\section{REFERÊNCIAS}

AZEVEDO, Rodrigo. Manifesto aos empreendedores iniciantes. Endeavor - Brasil, [s.I.], 6 maio 2015. Disponível em: https://endeavor.org.br/institucional/manifesto/. Acesso em: 22 maio 2017.

BARKI, Edgard; COMINI, Graziella; CUNLIFFE, Ann; HART, Stuart L.; RAI, Sudhanshu. Social entrepreneurship and social business: retrospective and prospective research. Revista Administração de Empresas, São Paulo, v. 55, n. 4, p. 380-84, ago. 2015.

BAUMAN, Zygmunt. A sociedade individualizada: vidas contadas e histórias vividas. Rio de Janeiro: Zahar, 2008.

BOURDIEU, Pierre. Les structures sociales de l'économie. Paris: Seuil, 2014. 
BOURDIEU, Pierre. O capital social - notas provisórias. In: NOGUEIRA, Maria Alice; CATANI, Afrânio (Org.). Escritos de educação. Petrópolis, RJ: Vozes, 2007.

BOURDIEU, Pierre. O poder simbólico. Rio de Janeiro: Bertrand Brasil, 2003b.

BOURDIEU, Pierre. Questões de sociologia. Lisboa: Fim de Século, 2003a.

CASAQUI, Vander. A construção do papel do empreendedor social: mundos possíveis, discurso e o espírito do capitalismo. Galáxia, São Paulo, n. 29, p. 44-56, 2015.

CASAQUI, Vander. A transformação social nos discursos da cena empreendedora social brasileira: processos comunicacionais e regimes de convocação na mídia digital. Universitas Humanística, Bogotá, n. 81, p. 205-26, jan./jun. 2016.

DARDOT, Pierre; LAVAL, Christian. A nova razão do mundo: ensaio sobre a sociedade neoliberal. São Paulo: Boitempo, 2016.

DEY, Pascal; STEYAERT, Chris. The politics of narrating social entrepreneurship. Journal of Enterprising Communities: peoples and Places in the Global Economy, v. 4, n. 1, 2010, p. 85-108.

ÉPOCA NEGÓCIOS. Lemann, Telles e Sicupira: trio de bilionários brasileiros ganha R\$ 3,5 bilhões em apenas um dia Fev. 2015. Disponível em: http://epocanegocios.globo.com/Informacao/Resultados/ noticia/2015/02/lemann-telles-e-sicupira-trio-de-bilionarios-da-ambev-ganha-r-35-bi-em-apenas-umdia.html. Acesso em: 22 maio 2017.

HERVIEUX, Chantal; GEDAJLOVIC, Eric; TURCOTTE, Marie-France B. The legitimization of social entrepreneurship. Journal of Enterprise Communities: people and places in the global economy, v. 4, p. 37-67, 2010.

PROGRAMA DAS NAÇÕES UNIDAS PARA O DESENVOLVIMENTO. Mercados Inclusivos no Brasil - desafios e oportunidades do ecossistema de negócios. PNUD, 2015. Disponível em: http://www.iniciativaincluir.org. br/Public/upload/ckfinder/files/Relat\%C3\%B3rio.pdf. Acesso em: 22 maio 2017.

REIS, Eliana Tavares dos; GRILL, Igor Gastal. Mirada reflexiva e esforços propositivos às pesquisas sobre elites. In: REIS, Eliana Tavares dos; GRILL, Igor Gastal (Org.). Estudos sobre elites políticas e culturais reflexões e aplicações não canônicas. São Luís, MA: EDUFMA, 2016.

ROSOLEN, Talita; TISCOSKI, Gabriela Pelegrini; COMINI, Graziela Maria. Empreendedorismo social e negócios sociais: um estudo bibliométrico da produção nacional e internacional. Revista Interdisciplinar de Gestão Social, Salvador, v. 3, n. 1, p. 85-105, jan./abr. 2014.

SCHUMPETER, J. Capitalismo, socialismo e democracia. Rio de Janeiro: Zahar, 1984.

Sobre os autores:

Alexandre Barbalho: Professor dos PPGs em Sociologia e em Políticas Públicas da Universidade Estadual do Ceará (UECE) e em Comunicação da Universidade Federal do Ceará (UFC). E-mail: alexandrealmeidabarbalho@gmail.com, Orcid: http://orcid.org/0000-0003-4612-6162

Carolina do Vale Uchoa: Jornalista e mestre em Sociologia pela Universidade Estadual do Ceará (UECE). E-mail: dovale.carol@gmail.com, Orcid: http://orcid.org/0000-0002-6645-3032 
